\title{
Heat Waves in Belgrade and Niš
}

\author{
Miroslava Unkašević', Ivana Tošić ${ }^{1}$ \\ Received: November 2008 | Revised: January 2009 | Accepted: January 2009
}

\begin{abstract}
In this study, heat waves at two meteorological stations in Serbia are analysed based on daily maximum temperatures in July and August. The warmest summers as regards heat wave duration and severity occurred within the periods 1946-1952, 19881998 (especially 1992-1995) and 2000-2003. The longest heat waves were recorded in 1952, lasting 53 days in Belgrade and 62 days in Niš. The summers of 1994 in Belgrade and 2003 in Niš are characterized with the highest numbers of consecutive tropical days (21 and 29, respectively).

The first-order autoregressive model is applied to generate long series of the daily maximum temperature, from which the relative frequencies of heat waves are estimated. The relationships between the typical and longest heat waves, and the circulation conditions are analysed using the Hess-Brezowsky catalogue of macrocirculation types.
\end{abstract}

Key words: heat waves, daily maximum temperature, autoregressive model, macrocirculation, Hess- Brezowsky classification, Serbia

\section{Introduction}

Many research activities during the $20^{\text {th }}$ century focused on extreme climate phenomena, including heat waves, because of their influences on ecosystems and human society (agriculture, water resources, energy demand and human mortality). The impact of extreme events is more serious when the extreme weather conditions prevail over extended periods. For this reason, prolonged extreme temperature events (usually referred to as heat waves and cold spells) have frequently been investigated (Colombo et al., 1999; Huth et al., 2000; Kyselý, 2002; Beniston and Stephenson 2004).

High summer temperatures are harmful to human health. The most frequent exceedances of threshold temperatures above which mortality rises significantly were observed in the 1930s-1940s in Chicago (Kunkel et al., 1999).

During the 1980 os and 1990s, unusually hot summers were recorded in Europe. Especially, the summer seasons of 1994 and 1995 established many record-breaking temperatures in a large number of cities across Europe and USA (Whitman et al. 1997).

Also, from June to August in 2003, record-breaking high temperatures were reported across Europe, including Spain, the Netherlands, Switzerland, France, Germany and England (Jendritzky et al., 2003; Martinez Navarro et al., 2004; Fischer et al., 2004; Stedman, 2004). France was the Euro- pean country most affected by the heat wave, according to the registered rate of mortality.

The aims of this study are to analyse heat waves in Serbia based on the daily maximum temperatures $\left(T_{\mathrm{m}}\right)$ in July and August. The analysis covers the period of the last 60 years at two meteorological stations in Serbia. Extreme high temperature events and heat waves are analysed. The frequency and persistence of heat waves are examined applying the first order autoregressive [AR(1)] model. AR(1) model results and observed characteristics are compared. Relationships between heat waves and the European atmospheric circulation are analysed. The conclusions are shown at the end of the paper.

\section{Data and Methods}

\section{Data}

The observations were taken at the Belgrade Meteorological Observatory $\left(\phi=44^{\circ} 48^{\prime} \mathrm{N}, \lambda=20^{\circ} 28^{\prime} \mathrm{E}, \mathrm{h}=132 \mathrm{~m}\right)$ and at Niš $\left(\phi=43^{\circ} 19^{\prime} \mathrm{N}, \lambda=21^{\circ} 54^{\prime} \mathrm{E}, \mathrm{h}=201 \mathrm{~m}\right)$. The analysis covers the periods 1943-2004 (Belgrade) and 1948-2004 (Niš). Belgrade and Niš are representative for a plain and a hilly region of Serbia, respectively. The climate of this area is continental. Niš is located south-east from Belgrade.

Daily $T_{\mathrm{m}}$ values of July and August are examined. Temperatures were measured using a Schneider thermometer.

1 University of Belgrade, Faculty of Physics, Departmentt. of Meteorology, 11000 Belgrade, Serbia; miroslava@ff.bg.ac.yu; itosic@ff.bg.ac.yu 
Technical and critical controls of these measurements were made by the National Meteorological Service. The stations were not moved during the study periods and the data sets have no missing records.

Series of daily temperatures observed in Belgrade and Niš have been used earlier by Domonkos et al. (2003) in their analysis of extreme temperature events in South and Central Europe. Seasonal means for July-August periods, and annual absolute maximum temperatures for Belgrade have been analysed by Unkašević and Tošić (2005).

\section{Heat wave definition}

First the concept of heat wave must be defined. Many definitions could apply to heat waves that quantify the duration and/or extremity of either night time minima or daytime maxima of temperatures (Karl and Knight, 1997; Huth et al., 2000; Palecki et al., 2001; Meehl and Tebaldi, 2004).

According to the heat wave definition by Huth et al. (2000), a heat wave is a continuous period during which:

1. the daily maximum air temperature is equal or higher than $30.0^{\circ} \mathrm{C}$ on at least 3 days;

2. the mean daily maximum air temperature over the whole period is higher than $30.0^{\circ} \mathrm{C}$, and

3. the daily maximum air temperature does not drop below $25.0^{\circ} \mathrm{C}$.

Tropical days refer to days with $T_{\mathrm{m}}$ reaching or exceeding $30.0^{\circ} \mathrm{C}$. According to the above definition of heat waves, two periods of tropical days separated by a slight drop of temperature constitute one heat wave. However, two periods of tropical days separated by a pronounced temperature drop below $25.0^{\circ} \mathrm{C}$ are treated as separate heat waves.

The modified auxiliary threshold of $28^{\circ} \mathrm{C}$ (instead of $25^{\circ} \mathrm{C}$ ) is introduced here, because Serbia has much warmer summer climate in comparison with Prague, the $28^{\circ} \mathrm{C}$ is just the median of the $T_{\mathrm{m}}$ values examined in this study).

\section{The Autoregressive model}

The first-order autoregressive model is frequently used to simulate time series of daily maximum temperatures and provide characteristics of heat waves and consecutive tropical days which are usually in good agreement with observations (Mearns et al., 1984; Macchiato et al., 1993, Colombo et al., 1999; Kyselý, 2002).

It is assumed that the sequence of daily maximum temperatures constitutes a realization from a first-order autoregressive process. Letting $T_{\mathrm{m}}(t)$ denote the maximum temperature on day $t$, an $\mathrm{AR}(1)$ process requires that the conditional probability distribution of $T_{\mathrm{m}}(t)$, given the past record of observed daily maximum temperatures, $T_{\mathrm{m}}(t-1)$, $T_{\mathrm{m}}(t-2) \ldots$, depends only on $T_{\mathrm{m}}(t-1)$, i.e. the observed maximum temperature for the previous day:

$$
T_{m}(t)-\mu=a_{1}\left(T_{m}(t-1)-\mu\right)+w_{t},
$$

where the daily maximum temperatures are expressed in terms of deviations from their common mean $\mu$, and $a_{1}$ denotes the first-order autocorrelation coefficient. The error terms $\left(w_{\mathrm{t}}\right)$ in $(1)$ are assumed to constitute a "white-noise" process, i.e., they are uncorrelated random variables with zero mean and constant variance $\sigma_{w}^{2}$ equal to:

$$
\sigma_{w}^{2}=\left(1-a_{1}^{2}\right) \sigma^{2}
$$

where $\sigma^{2}$ denotes the variance of $T_{\mathrm{m}}(t)$. The first-order autocorrelation coefficient is estimated according to Kendall and Stuart (1976):

$$
\hat{a}_{1}=\frac{\sum_{t=1}^{L-1} l(t+1) l(t)}{\sqrt{\sum_{t=1}^{L-1} l^{2}(t) \sum_{t=1}^{L-1} l^{2}(t+1)}}, t=1, \ldots, L,
$$

where $L$ represents the size of the time series at each station, while $l$ stands for the standardized variable:

$$
l(t)=\frac{T_{m}(t)-\mu}{\sigma} .
$$

Although the daily maximum temperature time series are clearly non-stationary because seasonal cycles are present, the stationary assumption is a reasonable approximation when dealing with July-August periods only (Mearns et al., 1984).

Then, the AR(1) model is applied to generate a synthetic time series of daily maximum temperatures, from which the probabilities and return periods of long heat waves are estimated.

\section{Macrocirculation classification}

Circulation conditions are analysed using the Hess-Brezowsky catalogue of subjectively classified large-scale circulation patterns (Hess and Brezowsky, 1952; Gerstengarbe et al., 1999). The Hess-Brezowsky classification is based on the positions of large high and low pressure systems relative to Germany. This classification recognizes three groups of circulations (zonal, half-meridional and meridional) divided into ten major types and 29 subtypes. Any circulation type persists for several days. The Hess-Brezowsky classification is often used for quite distant areas relative to Germany, because i) the classification is usable in much larger area than one country, and ii) the HessBrezowsky catalogue is long, complete and homogeneous, thus it is a popular tool for climatological investigations. This catalogue of large-scale circulation patterns is commonly used to characterise the relations between local weather and European circulation (e.g. Domonkos et al. 2003; James, 2006).

The present analysis is carried out for nine groups of cicrulation types, because the SE major type didn't exist in summer. The analysed major types are: west (W), central European high (HM), southwest (SW), south (S), north (N), northwest (NW), northeast (NE), east (E) and central European low (TM).

\section{Results}

\section{Extreme high temperatures}

The highest temperatures in Belgrade were observed in 1988 $\left(40.2^{\circ} \mathrm{C}\right)$ and in $2000\left(40.5^{\circ} \mathrm{C}\right)$, while in Niš in 1952 and 1994 $\left(42.2^{\circ} \mathrm{C}\right)$. According to the temperature observations in July 2007, the former highest temperatures recently have been 


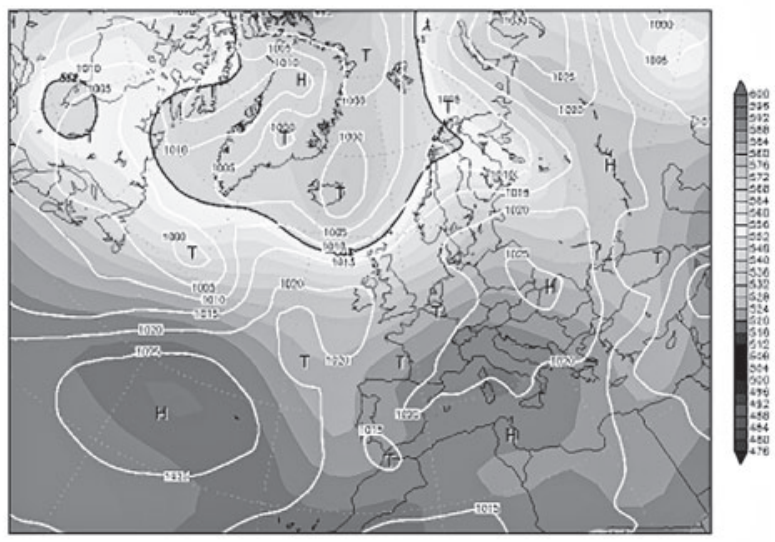

Figure 1 Height of $500 \mathrm{hPa}$ surface (gpm) and sea level pressure (hPa) at July 30, 1992 at oo UTC

exceeded $\left(43.6^{\circ} \mathrm{C}\right.$ in Belgrade and $43.2^{\circ} \mathrm{C}$ in Niš). The new records will be the subject of a future investigation.

Most extreme temperatures in Belgrade were confined to relatively short duration heat waves (15 days in 1988 and 12 days in 2000), with a cumulative excess (sum of $T_{\mathrm{m}}$ above $30.0^{\circ} \mathrm{C}$ ) of $38.2^{\circ} \mathrm{C}$ and $39.5^{\circ} \mathrm{C}$, respectively, not reaching a severity comparable to those of 1946 and 1992 (Table 1a). However, the highest temperatures in Niš were accompanied with longer duration heat waves, 62 days (1952) and 41 days (1994), as can be seen from Table 1b. In 1992, the longest periods (42 days in Belgrade and 40 days in Niš) with high air temperature and low interdiurnal temperature variability were related to persistent circulation patterns over Europe, with a high-pressure system influencing central Europe and the Balkan (Fig. 1).

The total number of tropical days (days with the daily maximum temperatures exceeding threshold value of $30^{\circ} \mathrm{C}$ ) for Belgrade and Niš is illustrated in Fig. 2. We can see an increase until 1952 and after 1975, while a minimum appears from 1965 to 1985 for both meteorological stations. Based on surface temperature data from 100 European stations, ECSN (1995) reports a temperature increase from the beginning of the $2 \mathrm{O}^{\text {th }}$ century until 1940 , a period of stabilization or even cooling until around 1970, followed by a new increase extending up to the present time. Our results co-

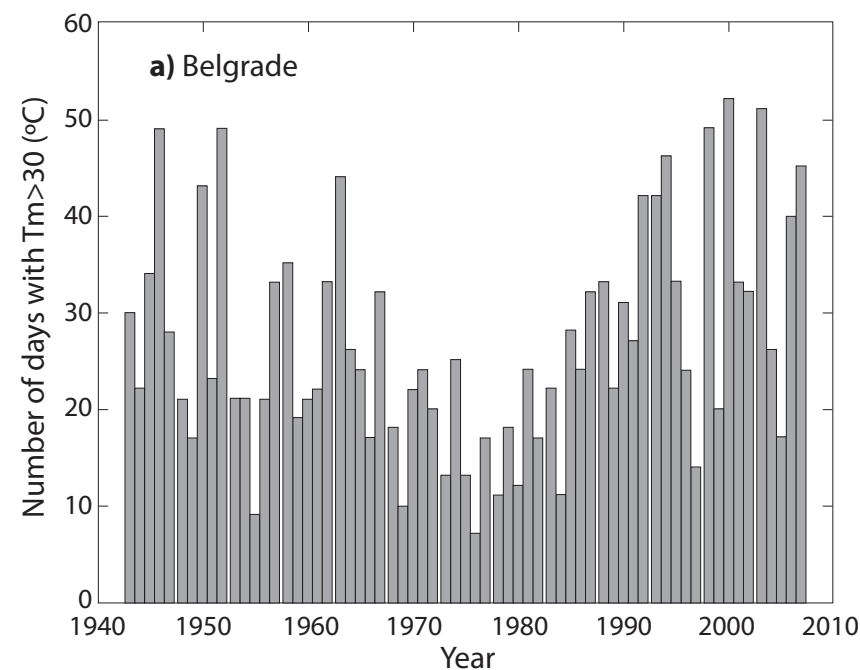

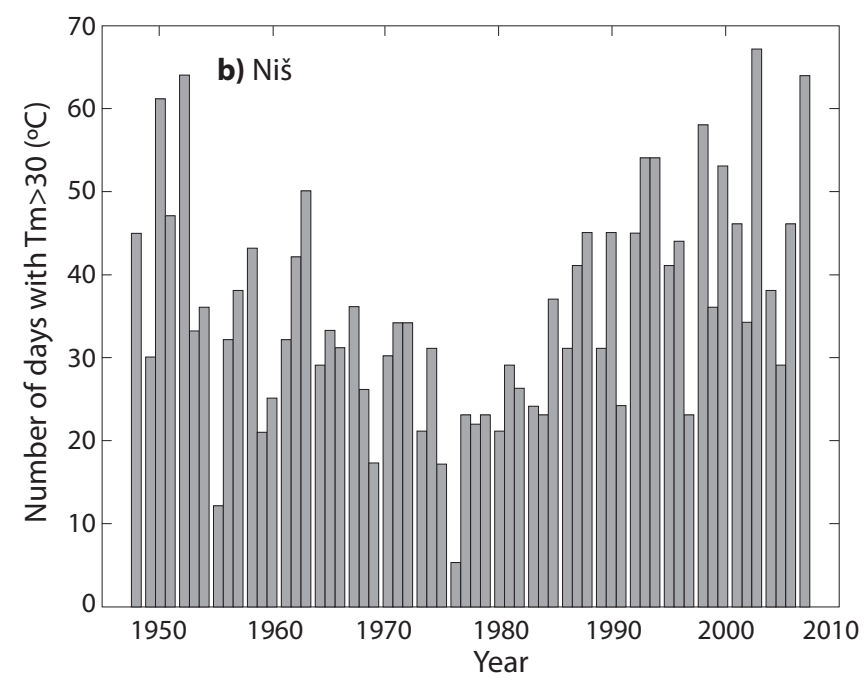

incide with ECSN (1995) and the analysis of Founda et al. (2004) for Athens.

The number of tropical days is greater in Niš than in Belgrade, as a consequence of more continental climate in Niš. It was calculated that the total number of tropical days in Belgrade during the last decade (1995-2004) is 259 days, with the same parameter being 1300 days for the whole record. This means that $20 \%$ of the tropical days for the whole period examined occurred during the last 10 years. This proportion is $21 \%$ for Niš.

\section{Observed heat waves}

To characterize heat waves in Serbia, the duration, the peak temperature and the cumulative $T_{\mathrm{m}}$ excess above $30.0^{\circ} \mathrm{C}$ during heat waves are used. The cumulative $T_{\mathrm{m}}$ excess is one of the most appropriate variable to characterize the severity of heat waves (see e.g. Kyselý, 2002).

The longest heat waves in Belgrade were recorded in 1952 (lasting 53 days) and 1992 (42 days), which are represented in Fig. 3a,b. Then, the heat waves recorded in 1946 and 1995 ( 38 days), 2000 (34 days), and 1994 and 2003 with a duration of 29 days follow (Table 1a). In the southeast the durations of the most persistent heat waves are longer $(\mathrm{Ta}-$ ble $1 b)$. The longest heat waves with durations of 62 and 54 days were observed in Niš in 1952 and 1988, respectively (Fig. 3c,d). The next longest heat waves were observed in 2003, 1948, 1994 and 1998 (41-43 days, Table 1b). The most severe heat waves in terms of the cumulative $T_{\mathrm{m}}$ excess above $30.0^{\circ} \mathrm{C}$ were in $1946\left(150.2^{\circ} \mathrm{C}\right.$, Table 1a) in Belgrade and in $1952\left(302.0^{\circ} \mathrm{C}\right.$, Table $\left.1 \mathrm{~b}\right)$ in Niš.

Summers of 1994 and 2003 have been mentioned among the hottest summers observed in Europe. As for Serbia, the summer of 1994 in Belgrade and that of 2003 in Niš were characterized with the highest numbers of consecutive tropical days (21 and 29, respectively, Table 1).

The mean July-August daily maximum temperature expressed as an anomaly from the long-term mean (AJA) is also given in Table 1. In terms of AJA most of the warmest summers in Serbia occurred within the periods 1946-1952, 1988-1998 (especially 1992-1995) and 2000-2003. Similar results were obtained for large regions in Europe by other researchers. Analyzing low-frequency fluctuations for many

Figure 2 Annual numbers of tropical days $\left(T_{m} \geq 30^{\circ} \mathrm{C}\right)$ a) Belgrade and b) Niš 
a)
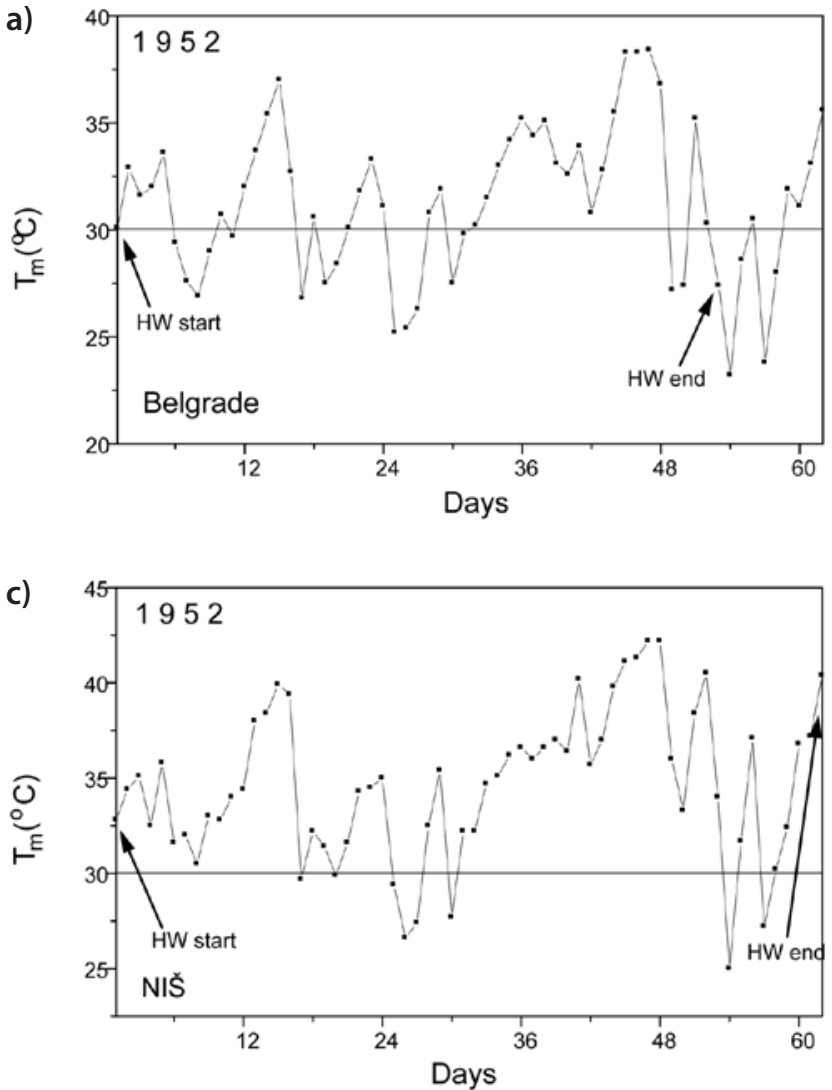

b)
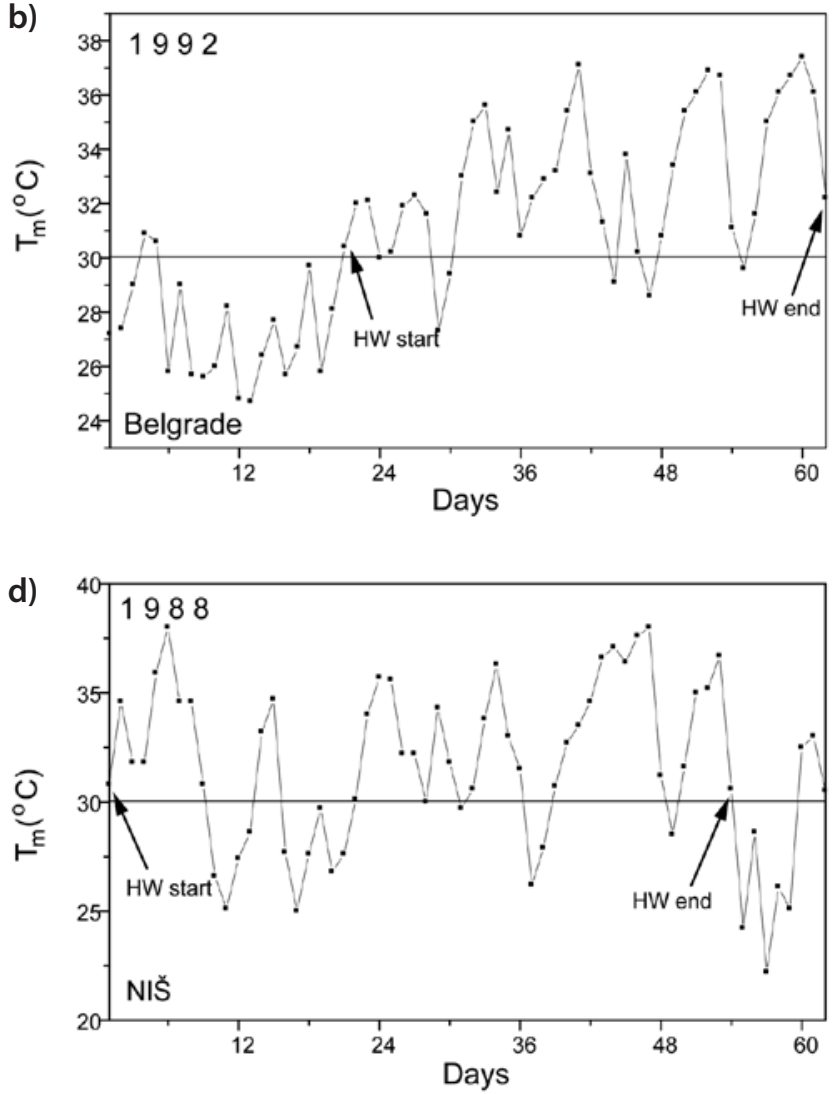

Figure 3 The longest heat waves (HW) observed in: $a, b$ ) Belgrade and c, d) Niš

Table 1 The longest and most severe heat waves (as measured by cumulative $T_{m}$ excess above $30.0^{\circ} \mathrm{C}$, TS30) in: a) Belgrade (19432004) and b) Niš (1948-2004). NT30 - number of consecutive days with temperature above $30.0^{\circ} \mathrm{C}$, AJA - mean July-August $T_{m}$ anomaly from the long-term mean, HITV - highest rise and drop in the interdiurnal $T_{\mathrm{m}}$ variability

\begin{tabular}{|c|c|c|c|c|c|c|c|}
\hline \multirow{2}{*}{$\begin{array}{l}\text { Beginning } \\
\text { and year }\end{array}$} & \multirow{2}{*}{$\begin{array}{l}\text { Duration } \\
\text { (days) }\end{array}$} & \multirow{2}{*}{$\begin{array}{c}\text { TS30 } \\
\left({ }^{\circ} \mathrm{C}\right)\end{array}$} & \multirow{2}{*}{$\begin{array}{c}\text { NT30 } \\
\left({ }^{\circ} \mathrm{C}\right)\end{array}$} & \multirow{2}{*}{$\begin{array}{c}\text { Peak T } \\
\left({ }^{\circ} \mathrm{C}\right)\end{array}$} & \multirow{2}{*}{$\begin{array}{l}\text { AJA } \\
\left({ }^{\circ} \mathrm{C}\right)\end{array}$} & \multicolumn{2}{|c|}{$\operatorname{HITV}\left({ }^{\circ} \mathrm{C}\right)$} \\
\hline & & & & & & rise & drop \\
\hline \multicolumn{8}{|l|}{ a) Belgrade } \\
\hline 1.7 .1952 & 53 & 120.9 & 17 & 38.4 & 3.32 & 7.8 & -9.6 \\
\hline 21.7.1992 & 42 & 126.7 & 13 & 37.4 & 3.12 & 4.7 & -5.6 \\
\hline 9.7.1995 & 38 & 34.9 & 7 & 34.3 & 1.08 & 3.9 & -5.3 \\
\hline 17.7.1946 & 38 & 150.2 & 18 & 39.3 & 3.68 & 8.2 & -8.8 \\
\hline 23.7.2000 & 34 & 116.4 & 15 & 40.0 & 2.86 & 4.0 & -6.5 \\
\hline 16.7.1994 & 29 & 80.4 & 21 & 38.9 & 2.46 & 2.5 & -8.0 \\
\hline 3.8.2003 & 29 & 80.3 & 8 & 38.4 & 2.40 & 6.3 & -6.1 \\
\hline \multicolumn{8}{|l|}{ b) Niš } \\
\hline 1.7.1952 & 62 & 302.0 & 23 & 42.2 & 5.53 & 6.7 & -9.9 \\
\hline 1.7.1988 & 54 & 149.4 & 10 & 38.0 & 2.49 & 4.6 & -7.0 \\
\hline 20.7.2003 & 43 & 166.3 & 29 & 40.5 & 3.47 & 8.4 & -9.5 \\
\hline 18.7.1998 & 41 & 160.7 & 21 & 39.7 & 2.34 & 5.8 & -11.5 \\
\hline 16.7.1994 & 41 & 130.5 & 22 & 42.2 & 2.36 & 6.8 & -8.0 \\
\hline 20.7 .1948 & 41 & 121.0 & 12 & 41.5 & 1.89 & 6.8 & -9.3 \\
\hline 23.7.1992 & 40 & 148.3 & 17 & 38.0 & 2.56 & 2.9 & -5.9 \\
\hline 22.7.1967 & 37 & 65.7 & 6 & 37.4 & 0.69 & 4.8 & -9.4 \\
\hline 1.7 .1950 & 35 & 135.2 & 7 & 40.7 & 4.60 & 6.7 & -10.7 \\
\hline 23.7.2000 & 34 & 155.0 & 16 & 40.2 & 3.46 & 4.2 & -8.7 \\
\hline
\end{tabular}


Table 2 Return periods (years) of heat waves lasting 3, 5, 7, 10, 15, 20, 25 and 30 days for Belgrade and Niš

\begin{tabular}{|l|r|r|r|r|r|r|r|r|}
\hline Stations / days & 3 & 5 & 7 & 10 & 15 & 20 & 25 & 30 \\
\hline Simulated (Bgd) & 0.1 & 0.3 & 0.6 & 1.7 & 8.4 & 38.7 & 172.1 & 481.9 \\
\hline Observed (Bgd) & 0.1 & 0.3 & 0.4 & 1.0 & 2.9 & 8.6 & 18.5 & 31.1 \\
\hline Simulated (Niš) & 0.1 & 0.3 & 0.6 & 1.4 & 8.3 & 33.5 & 148.9 & 855.0 \\
\hline Observed (Niš) & 0.1 & 0.3 & 0.5 & 1.0 & 2.9 & 5.5 & 9.0 & 14.4 \\
\hline
\end{tabular}

sites in Europe (including Belgrade and Niš for the period 1949-1998), Domonkos et al. (2003) found that the highest frequencies occurred in the late 1940 s and in the latest decade, whereas the lowest frequency was around the late 1970s. Xoplaki et al. (2003) investigated summer air temperature variability over Greece and western Turkey, and pointed out that the summer air temperature of the area is characterised by warm 1950 s and 1990 s and rather cool 1960 , 1970 s and early 1980 s.

Interdiurnal temperature variability during long heat waves is important for human health. The highest interdiurnal rises and drops of the maximum temperatures during the longest heat waves at Belgrade and Niš are shown in the last column of Table 1 . It can be seen that the interdiurnal drop (in absolute value) was always greater than the interdiurnal rise, with one exception only. The values of interdiurnal rise were between $2.5^{\circ} \mathrm{C}$ and $8.4^{\circ} \mathrm{C}$, while the values of interdiurnal drop varied from $-5.3^{\circ} \mathrm{C}$ to $-11.5^{\circ} \mathrm{C}$. The interdiurnal drops of $T_{\mathrm{m}}$ in Niš were usually higher, than that in Belgrade. The highest interdiurnal drop of $T_{\mathrm{m}}$ recorded in Belgrade in 1952 during the longest heat wave occurred when a western and central European air pressure trough existed, while in Niš in 1998, it occurred when a cyclone dominated over Western Europe.

\section{AR(1) model results}

Simulated frequencies of heat waves were determined from a 3,000-year long series. The distributions of the lengths of heat waves obtained using the $\mathrm{AR}(1)$ model for Belgrade and Niš are analysed. The AR(1) model slightly overestimates the percentage of heat waves lasting up to 6 days for
Belgrade and Niš. The percentage of long heat waves appears to be simulated well.

Return periods of heat waves lasting 10, 15, 20, 25 and 30 days are shown in Table 2. For example, the return period for a heat wave lasting 20 days is 39 years for Belgrade and 33 years for Niš, according to the AR(1) simulation. The estimated return periods for longest heat waves should be treated as upper limits because of deficiencies in simulating the temperature variability, which are inherent in the $\mathrm{AR}(1)$ model (see also Kyselý, 2002).

On changing the third condition of the heat wave definition (daily maximum air temperature does not drop below $28.0^{\circ} \mathrm{C}$ ), better results are obtained (Fig. 4). As a consequence of this modification, the duration of the longest heat waves becomes shorter, i.e., 32 days in Belgrade and 40 days in Niš. Using this definition, the relative frequencies of typical heat waves, lasting 3-4 days both in Belgrade and Niš, are better approximated by the AR(1) model, while the overestimations for return periods of the longest heat waves are similar to the ones discussed above.

\section{Relationship between heat waves and atmospheric circulation}

The relationship between the longest and typical heat waves, and the circulation conditions are analysed using the HessBrezowsky catalogue of large-scale circulation patterns. Relative frequencies of circulation types during longest and typical heat waves are shown in Figures 5 and 6, respectively. Almost $33 \%$ of the longest heat wave days in Belgrade and $31 \%$ in Niš occurred under major type W (Fig. 5). Also, circulation from the west contributes to typical heat waves of
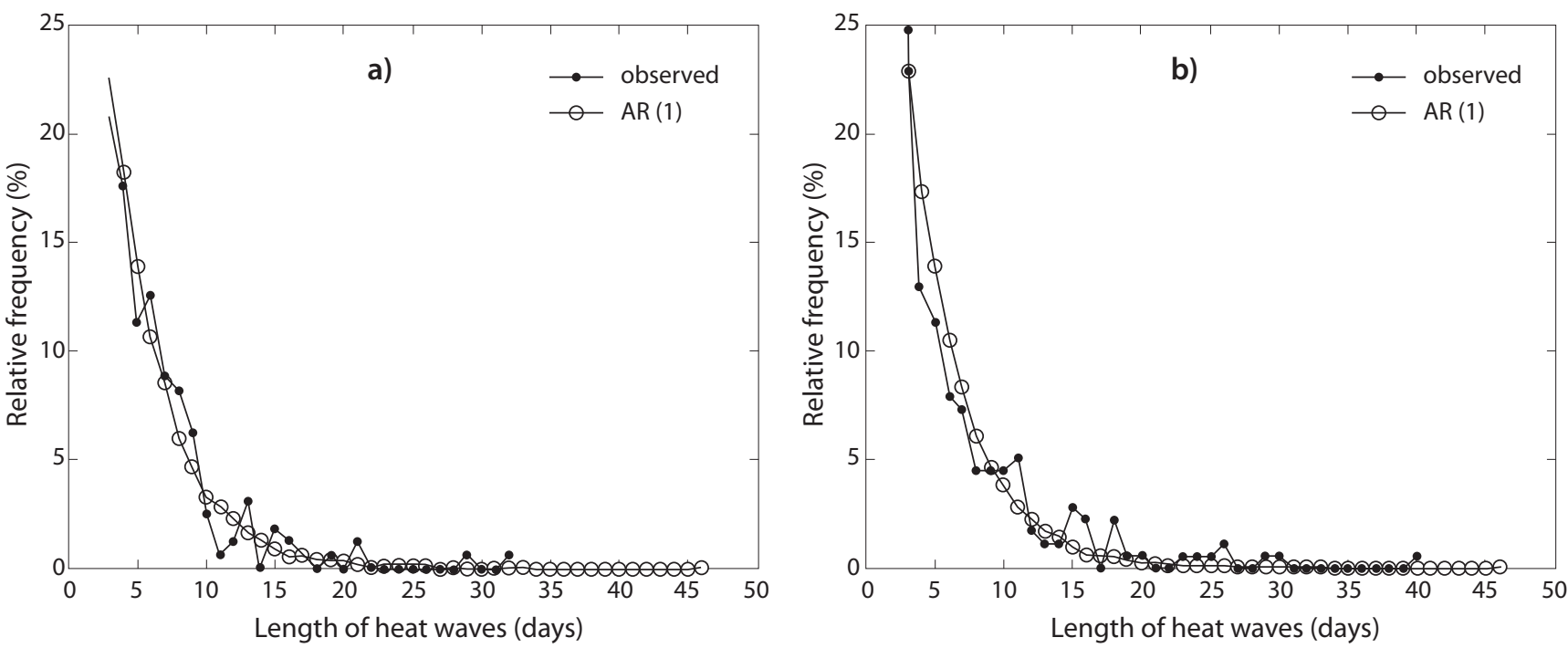

Figure 4 Distribution of simulated and observed heat waves lengths with the modified condition: daily maximum air temperature does not drop below $28.0^{\circ} \mathrm{C}$ during heat waves. a) Belgrade and b) Niš 


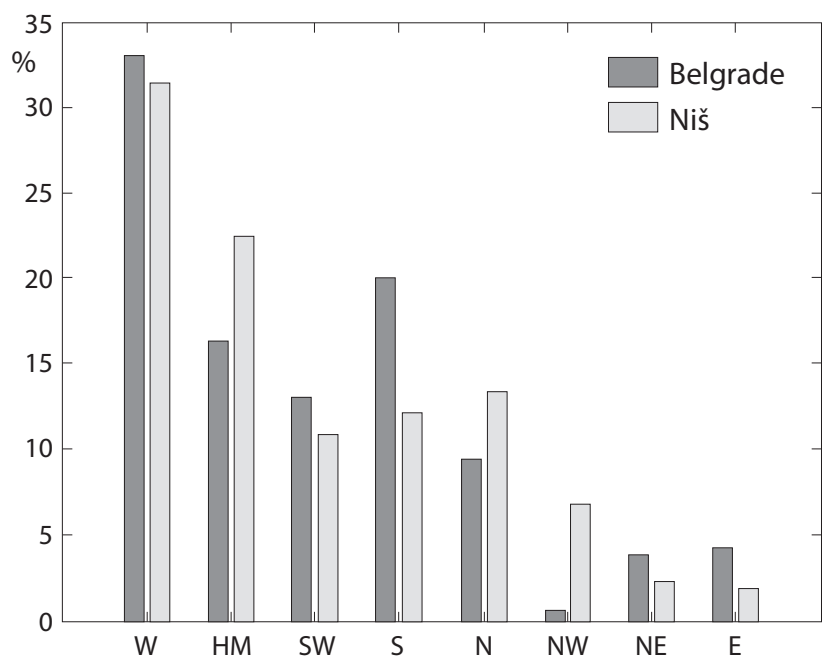

Figure 5 Relative frequencies (\%) of prevailing Hess-Brezowsky major types during the longest heat waves in: a) Belgrade and b) Niš. W - west, HM - Central European high, SW - southwest, $\mathrm{S}$ - south, N - north, NW - northwest, NE - northeast, E - east, and TM - central European low

about $30 \%$ in Belgrade and $25 \%$ in Niš (Fig. 6). Further $24.5 \%$ of typical heat waves in Niš occurred under major type $\mathrm{N}$.

Xoplaki et al. (2003) pointed out that the extremely warm summers in Greece and western Turkey are associated with subsidence and stability, anomalous advection from northeast at the mid and upper troposphere and anomalous westerly air flow in the lower troposphere, and decreased frequency and intensity of northerly winds in the lower troposphere.

Baldi et al. (2006) have shown that the heat waves in the Central Mediterranean are associated with the presence of a jet stream located in the north of the Alps and an anticyclonic vortex over the Mediterranean, which forces a strong subsidence and an adiabatic warming of the troposphere over the Mediterranean.

\section{Conclusions}

An analysis of heat waves in Serbia was performed. Based on the AR(1) model, the relative frequencies of heat waves were computed and compared to that estimated from the observed data. The relationship between the longest and typical heat waves, and the circulation conditions was analysed using the Hess-Brezowsky catalogue of macrocirculation types. From the analysis of heat waves in Serbia, it can be concluded that:

- The warmest summers with regards to heat wave duration and severity occurred within the periods 1946-1952, 1988-1998 (especially 1992-1995) and 2000-2003; The low frequency changes of summer heat occurrences in Serbia turned out to be similar to that in other parts of central and southern Europe.

- A longer duration of heat waves and periods of successive tropical days were recorded in Niš in comparison with Belgrade, suggesting the effect of more continental climate in Niš;

- The annual number of tropical days has an increasing tendency until 1952 and after 1975;

- The AR(1) model is able to reproduce the main characteristics of heat waves in Belgrade and Niš, but the chance of extremely long heat waves is underestimated;

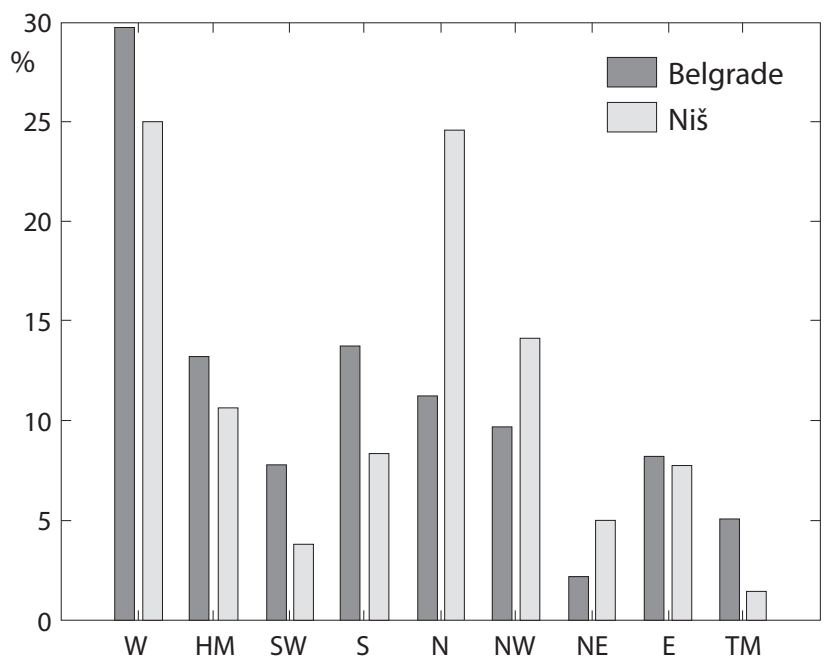

Figure 6 The same as Fig.5, but for typical heat waves

- Almost 33\% of the longest heat wave days in Belgrade and $31 \%$ in Niš occurred under the major type W of the HessBrezowsky classification

- Major type $\mathrm{W}$ is also prevailing during typical heat waves, though $24.5 \%$ of the typical heat wave days in Niš occurred under the major type $\mathrm{N}$.

Barnett et al. (1999) concluded that the most probable cause of the observed warming of the atmosphere since 1970 is a combination of internally and externally forced natural variability and anthropogenic sources. We hope that the results of the study contribute to the better understanding of the physical mechanisms yielding long heat waves which are expected to occur more frequently in the course of the twenty-first century, as suggested by regional climate scenarios (Beniston, 2004).

\section{Acknowledgements}

This study was supported by the Serbian Ministry of Science and Environmental Protection, under Grant 1460o6. The reviewer made useful comments and with his suggestions helped to improve the quality of the paper.

\section{References}

Baldi, M., Dalu, G., Maracchi, G., Pasqui, M., Cesarone, F. 2006. Heatwaves in the Mediterranean: A local feature or a large scale effect? International Journal of Climatology 26: 1477-1487.

Barnett, T.P., Hasselmann, K., Chelliah, M., Delworth, T., Hegerl, G., Jones, P., Rasmusson, E., Roeckner, E., Ropelewski, C., Santer, B., Tett, S. 1999. Detection and attribution of recent climate change: a status report. Bulletin of the American Meteorological Society 80: 2631-2659.

Beniston, M., Stephenson, D.B. 2004. Extreme climatic events and their evolution under changing climatic conditions. Global and Planetary Change 44: 1-9.

Beniston, M. 2004. The 2003 heat wave in Europe. A shape of things to come? Geophysical Research Letters 31: L02022, DOI:10.1029/2003GL018857. 
Colombo, A.F., Etkin, D., Karney, B.W. 1999. Climate variability and the frequency of extreme temperature events for nine sites across Canada: Implications for power usage. Journal of Climate 12: 2490-2502.

Domonkos, P., Kyselý, J., Piotrowicz, K., Petrovic, P., Likso, T. 2003. Variability of extreme temperature events in south-central Europe during the 2oth century and its relationship with large scale circulation, International Journal of Climatology 23, 987-1010.

ECSN, First European Climate Assessment. 1995. ISDN 90369-2069-8 De Bilt, March 1995.

Founda, D., Papadopoulos, K.H., Petrakis, M., Giannakopoulos, C., Good, P. 2004. Analysis. of mean, maximum, and minimum temperature in Athens from 1897 to 2001 with emphasis on the last decade: trends, warm events, and cold events. Global and Planetary Change 44: 27-38.

Fischer, P., Brunekreef, B., Lebret, E. 2004. Air pollution related deaths during the 2003 heat wave in the Netherlands. Atmospheric Environment 38: 1083-5.

Gerstengarbe, F.W., Werner, P.C., Rüge, U. 1999. Katalog der Grosswetterlagen Europas nach Paul Hess und Helmuth Brezowsky 1881-1998. Deutscher Wetterdienst: Offenbach am Main.

Hess, P., Brezowsky, H. 1952. Katalog der Grosswetterlagen Europas. Ber. Dt. Wetterdienstes in der US-Zone, Nr. 33; $39 \mathrm{pp}$.

Huth, R., Kyselý, J., Pokorná, L. 2000. A GCM simulation of heat waves, dry spells, and their relationships to circulation. Climatic Change 46: 29-6o.

James, P.M. 2006: An assessment of European synoptic variability in Hadley Centre global environmental models based on an objective classification of weather regimes. Climate Dynamics 27, 215-231.

Jendritzky, G., Koppe, C., Pfaff, G. 2003. Die Hitzewelle 2003 in Westund Südeuropa. In: Bernhofer C, Godberg $\mathrm{V}$, editors. 5. FA BIOMET-Tagung Mensch-Pflanze-Atmospäre (3-5 Dezember 2003, Dresden): Tharandter Klimaprotokolle; 2003. p. 33- 35.

Karl, T.R., Knight, R.W. 1997. The 1995 Chicago heat wave: how likely is a recurrence? Bulletin of the American Meteorological Society 78: 1107-1119.

Kendall, M.G., Stuart, A. 1976. The Advanced Theory of Statistics. Vol. 3. Charles Griffin \& Co., London.
Kunkel, K.E., Pielke, R.A., Changnon, S.A. 1999. Temporal fluctuations in weather and climate extremes that cause economic and human health impacts - a review. Bulletin of the American Meteorological Society 80: 1077-1098.

Kyselý, J. 2002. Probability estimates of extreme temperature events: stochastic. modelling approach vs. extreme value distributions. Studia Geophysica et Geodaetica 46: 93-112.

Macchiato, M., Serio, C., Lapenna, V., La Rotonda, L. 1993. Parametric time series analysis of cold and hot spells in daily temperature: An application in southern Italy. Journal of Applied Meteorology 32: 1270-1281.

Martinez Navarro, F., Simon-Soria, F., Lopez-Abente, G. 2004. Evaluation of the impact of the heat wave in the summer of 2003 on mortality. Gaceta Sanitaria 18: 250-8.

Mearns, L.O., Katz, R.W., Schneider, S.H. 1984. Extreme high temperature events: changes in their probabilities with changes in mean temperature. Jornal of Climate and Applied Meteorology 23: 1601-1608.

Meehl, G.A., Tebaldi, C. 2004. More intense, more frequent and longer lasting heat waves in the 21st century. Science 305: 994- 997.

Palecki, M.A., Changnon, S.A., Kunkel, K.E. 2001. The Nature and Impacts of the July 1999 Heat Wave in the Midwestern United States: Learning from the Lessons of 1995. Bulletin of the American Meteorological Society 82: 1353-67.

Stedman, J. 2004. The predicted number of air pollution related deaths in the UK during the August 2003 heatwave. Atmospheric Environment 38: 1087-90.

Unkašević, M., Tošić, I., 2005. Trends in extreme summer temperatures at Belgrade, Theor. Appl. Climatol., 82, 199205.

Whitman, S., Good, G., Donoghue, E.R., Benbow, N., Shou, W.Y., Mou, S.X. 1997. Mortality in Chicago attributed to the July 1995 heat wave. American Journal of Public Health 87: 1515-1518.

Xoplaki, E., González-Rouco, J.F., Gyalistras, D., Luterbacher, J., Rickli, R., Wanner, H. 2003: Interannual summer air temperature variability over Greece and its connection to the large-scale atmospheric circulation and Mediterranean SSTs 1950-1999. Climate Dynamics, 20, 537-554. 